\title{
Influence of Three Medicinal Plants Extract on The Histology of the Duodenum, Liver and Caecum of broiler chickens
}

\author{
Olorunsogbon B.F $\mathrm{F}^{\mathrm{a}^{*}}$ and Osho I.B

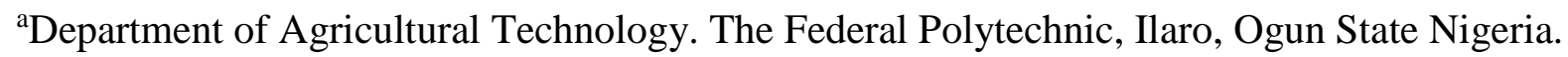 \\ ${ }^{b}$ Department of Animal Production and Health, Federal University of Technology, Akure. Ondo \\ State \\ Corresponding author: bernard.olorunsogbon@federalpolyilaro.edu.ng \\ Telephone: +2348034699991
}

\begin{abstract}
This study investigated the influence of three medicinal plants extract (Aristolochia ringens, Allium sativum and Occium grattissium) on the histology of the duodenum, liver and caecum of broiler chickens. A total of 300 marshal broiler chicks were used for this experiment. Birds were brooded for two weeks and the experiment lasted six weeks. The birds were distributed into five treatments; Treatment 1 (positive control, which received synthetic drug), treatment 2 (negative control, without antibiotic or phytobiotics), treatments 3 (herbal extract of A.ringens at $20 \mathrm{ml} / \mathrm{litre}$ of water), treatment 4 (herbal extract of Garlic (A.sativum) bulb at 20ml/litre of water) and treatment 5 (O.gratissium leaves extract at $20 \mathrm{ml} /$ litre of water). Each treatment was subdivided into three replicates consisting of 20 birds per replicate. Twenty percent $20 \%$ concentration of plant extracts were given at the rate of $20 \mathrm{ml}$ per liter of water Experiment was arranged in a Completely Randomized Design. On the $56^{\text {th }}$ day of experiment, one bird per replicate was slaughtered, skinned to remove segments $(1 \mathrm{~cm})$ were removed from the duodenum and caecum and part of the liver was cut. The segments were examined by light microscope to determine the histological differences. Inclusion of $20 \mathrm{ml}$ of Aristolochia ringens and Allium sativum aqueous extract into $1 \mathrm{ml}$ of water improved duodenal villi histology as well as the liver histology of broiler chickens at 56 days. Furthermore administration of the three medicinal plants extract Aristolochia ringens, Allium sativum and Occium grattissium at $20 \mathrm{ml} / \mathrm{litre}$ of water inclusion level had no deleterious effect on the caecum histology of broiler chickens. Hence, 20m1/litre of water inclusion level of aqueous extract of Aristolochia ringens, Allium sativum was recommended for improved intestinal histology and liver health of broiler chickens.
\end{abstract}

Keywords: Aristolochia ringens; Allium sativum; Occium grattissium; intestinal histology; liver histology; caecum histology; marshal broiler strain.

\subsection{INTRODUCTION}

Intestinal development and maturation are known to play a major role in poultry health, with a long-term effect on broiler performance (Sklan, 2001). Different types of antibiotics and chemotherapeutic agents are used in the treatment of diseases and as growth promoters in 
livestock production. The emergence of resistant bacteria drove the European Union to ban antibiotics usage in animal production (Yang et al., 2012). This situation motivated researchers to find new alternatives for antibiotics growth promoters, the possibility of antibiotics ceasing to be used as growth stimulants for poultry and the concern about the side effects of their use as therapeutic agents has produced a climate in which both consumer and manufacturer are looking for alternatives. Yang et al. (2012) opined that feed additives of plant origin with beneficial therapeutic helps in eliminating antibiotics from poultries diets (Yang et al., 2012), since they are rich source of essential nutrients (Yang et al., 2012), chemicals and other active component (Klaunig et al., 2003), leaving no residual effect or creating the occurrence of resistant microbes. Countries in West Africa especially Nigeria are richly blessed with forests containing arrays of different herbs, shrubs and trees. These plant materials have being used in recent years in poultry production. Natural products such as Aristolochia ringens, Allium sativum and Occium grattissium have the potential to improve broiler production because of their phytobiotc properties (Alexander. 2016; Divya et al., 2017 and Obanga et al., 2018).

Allium sativum, commonly known as garlic, belongs to the family Amaryllidaceae. Garlic and its preparations have been used extensively in health benefits, resulting in numerous research reports over the last decade alone. Garlic is widely consumed spices in food, while also consumed in the form of drink (Joshua et al., 2014). Garlic contains sulfur-containing compounds (Wichtl. 2004). The fresh bulb contains an alliin, allicin and volatile oils when the garlic clove is crushed, the odourless compound alliin is converted to allicin via the enzyme allinase. Allicin gives garlic its characteristic pungent smell (Joshua et al., 2014). It contains vitamins, minerals and trace elements (Divya et al., 2017). On the other hand, garlic is an herbal medicine which is used for prevention and treatment of many diseases such as, cold and flu symptoms through immune enhancement and exhibits anticancer, antioxidant, antiinflammatory, antimicrobial, anti-stress, hypocholesterolemic, hypoglycemic, and hypotensive activities. And it is used to treat diabetes, atherosclerosis, hyperlipidemia, and gastrointestinal infection (Divya et al., 2017).

Aristolochia ringens is a perennial plant in the Aristolochiaceae family. In the south-western Nigeria (Yoruba), the plant is commonly known as 'Akogun' (Obanga et al., 2018). The plant contains alkaloids and aristolochic acids. (Osho and Lajide 2014 and Mabberley 1993). The antimicrobial potential and phytochemical composition of Aristolochia ringens root and bark have been investigated (Fashola. 2015). In addition, Aristolochia ringens have been reported to be have various antioxidant and antimicrobial effects and also helped to reduce oxidative stress and loss of cellular function (Obanga et al., 2018).

The plant Ocimum gratissimum is one of those plants widely known and used for both medicinal and nutritional purposes (Alexander. 2016). Ocimum gratissimum is used through West Africa as anti- malarial and anti-convulsant. The crushed leaf juice is used in the treatment of conlvusion 
and stomach pain. Oil from the leaves have been found to possess antiseptics, antibacterial and antifungal activities (Edeoga and Eriata, 2001).

The beneficial effect of Allium sativum, Aristolochia ringens and Ocimum gratissimum on growth performance and immune response on broiler have been reported (Rifat et al., 2012 and Olorunsogbon. 2017), but there are limited reports on the influence of Allium sativum, Aristolochia ringens and Ocimum gratissimum on the intestinal histology of broiler chickens. Therefore, this study was aimed at determining the influence Allium sativum, Aristolochia ringens and Ocimum gratissimum extract on the duodenal, liver and caecum histology of broiler chickens.

\subsection{MATERIALS AND METHOD}

\subsection{Experimental site}

The experimental trial was carried out over a period of 56 days in a deep litter house at the Parasitology Unit of the Teaching and Research Farm of the Federal University of Technology, Akure (FUTA).

\subsection{Source and preparation of medicinal plant extract}

\subsubsection{Preparation of Allium Sativum extract}

$500 \mathrm{~g}$ of fresh garlic bulb cloves were purchased from the Local market in Akure, Ondo state were shade dried and peeled off. They were milled to a fine powder using a mechanical grinder. The powder was macerated with water for 24 hours. The extract was then filtered with filter paper (Whatman No. 1). Serial dilution was done to obtain $20 \%$ Allium Sativum extract (20ml of Allium Sativum extract into $80 \mathrm{ml}$ of distilled water) and the newly formed extract was stored in a refrigerator until when needed.

\subsubsection{Preparation of Aristolochia ringens extract}

The air-dried leaves of Aristolochia ringens, was pulverized and the powdered materials (500g) was macerated with 1 litre of water for 24 hours. The extract was then filtered with a filter paper. Serial dilution was done to obtain 20\% Aristolochia ringens extract (20ml of Aristolochia ringens extract into $80 \mathrm{ml}$ of distilled water) and the newly formed solution was kept in a darkcolored recipient (to prevent photolysis due to light penetration) and then stored in the refrigerator.

\subsubsection{Preparation of extract Ocimum gratissimum extract}

The air-dried leaves of Ocimum gratissimum, was pulverized and the powdered materials $(500 \mathrm{~g})$ was macerated with 1 litre of water for 24 hours. The extract was then filtered with a filter paper. Serial dilution was done to obtain $20 \%$ Ocimum gratissimum extract $(20 \mathrm{ml}$ of Ocimum 
gratissimum extract into $80 \mathrm{ml}$ of distilled water) and the newly formed solution was kept in a dark-colored recipient (to prevent photolysis due to light penetration) and then stored in the refrigerator.

\subsection{Experimental animal and design}

A total of 300 marshal broiler chicks, obtained from a reputable hatchery in Oyo state. Birds were brooded for two weeks and the experiment lasted 6 weeks. The birds were divided into 5 treatments. Treatment 1 served as the positive control which received synthetic drug, treatment 2 served as negative control, treatments 3 received herbal extract of A.ringens at $20 \mathrm{ml} / \mathrm{litre}$ of water, treatment 4 received herbal extract of Garlic (A.sativum) bulb at 20ml/litre of water and treatment 5 received O.gratissium leaves extract at $20 \mathrm{ml} /$ litre of water. Each treatment had three replicates of 20 birds per replicate. Twenty percent $20 \%$ concentration of plant extracts were given at the rate of $20 \mathrm{ml}$ per liter of water. These were served prophylactically for four weeks before the birds were challenged with coccidial oocyst and continuous as therapeutics. The experiment was in a Completely Randomized Design (CRD). Feed and water were supplied ad libitum and all necessary vaccination was given.

\subsection{Histology Examination}

At the $56^{\text {th }}$ day of experiment, one bird per replicate was slaughtered, skinned to remove segments of the small intestine, liver and caecum. Samples from the three treatments were dehydrated, cleared, and embedded in $10 \%$ formalin $(100 \mathrm{ml}$ formalin, $900 \mathrm{ml}$ distilled water). Segments $(1 \mathrm{~cm})$ were removed from the duodenum and caecum and part of the liver was cut. The segments were examined by light microscopy (Uni et al., 1998) with $10 \times 10$ magnification to determine the histological differences.

\subsection{Results and Discussion}

3.1 Effect of administration of Aristolochia ringens, Allium sativum, and Occium grattissium on duodenal villi histology of broiler chickens

The effect of administration of Aristolochia ringens, Allium sativum, and Occium grattissium on duodenal villi histology of broiler chickens at 56 days of age is presented in Plate 1, 2, 3, 4 and 5. The results gotten from the histology of the duodenum shows no visible lesion or degeneration in the villus and crypts of birds administered Aristolochia ringens, Allium sativum and birds not administered either antibiotics or phytobiotcs (negative control), while the villus of birds administered antibiotics (positive control) showed severe erosion and appeared stunted. The duodenal villi histology of birds administered Occium grattissium also showed severe erosion at the tail end of the villi and erosion of the crypts. These results supported the study of Diarra and 
Malouin. (2014) that use of antibiotics in poultry production increases the selection pressure for antibiotic-resistant bacteria, and these bacteria are mostly stored in the small intestine, thus can negatively affect the intestinal tissues. Birds administered Allium sativum and Aristolochia ringens had better representation of the villi as well as enhanced intestinal histological development observed in birds with numerous tall intestinal villi, intact enterocytes and slightly high and more prominent crypts in the small intestine villi histology as a result of administration of Aristolochia ringens as well as Allium sativum. The improved villi histology result can be adduced to the presence of linoleic acid, flavonoid and phenolic acid in Allium sativum and Aristolochia ringens which helps in biosynthesis of glands and cell membrane and also the tissue protection ability and antioxidant ability of these compounds present in Allium sativum and Aristolochia ringens. Also, the antioxidant ability of Allium sativum due to the presence of vitamin $\mathrm{C}$ aided the improved villi histological representation. Results corroborated the study of Faisal et al. (2019) that reported that use of phytobiotics alone as a replacement for anitibiotcs can improve intestinal health and development of broilers. Ripon et al. (2019) also reported that use of phytobiotcs in broiler production is beneficial for intestinal health of broilers.

\subsection{Effect of administration of Aristolochia ringens, Allium sativum, and Occium grattissium on} liver histology of broiler chickens

Plate 6, 7, 8, 9 and 10 revealed the histology of the liver of broiler chickens at 56 days of age administered phytobiotics. Result of the histology of the liver of broiler under the positive control group showed mild erosions of the hepatocellular atrophy with the hepatocyte not closely packed, while the liver histology of broilers under the negative control group showed moderate diffuse vacuolar hepatocellular degeneration. A hepatocyte is a cell of the main parenchymal tissue of the liver. Hepatocytes make up 55-65\% of the liver's mass. These cells are involved in: Protein synthesis. (Richard Bowen. 2001). Hepatocytes are also the chief functional cells of the liver and perform an astonishing number of metabolic, endocrine and secretory functions. Roughly $80 \%$ of the mass of the liver is contributed by hepatocytes. (Richard Bowen. 2001). Heat stress and the fat content in the feed can be adduced as the reason why the hepatocyte in the liver histology of broilers under the control groups were not closely packed.

Aristolochia ringens and Allium sativum has been reported to be very rich in various antioxidating enzymes such as linoleic acid, flavonoid, phenolic acid, catalase, glutathione 
peroxidase, and glutathione reductase (Divya et al., 2017; Obanga et al., 2018), thus preventing cellular damage.

3.3 Effect of administration of Aristolochia ringens, Allium sativum, and Occium grattissium on caecum histology of broiler chickens

The effect of administration of Aristolochia ringens, Allium sativum, and Occium grattissium on duodenal villi histology of broiler chickens at 56 days of age is presented in Plate 11, 12,1 3, 14 and 15. No visible lesion was observed in the histology of the caecum. This proves that all medicinal plants used for this experiment had no detrimental effect on the caecum tissue of broiler chickens.

\section{Conclusion and Recommendation}

Based on the findings of this experiment, it can be concluded that administration of Aristolochia ringens and Allium sativum improved the intestinal and liver health of broiler chickens. Therefore, Aristolochia ringens and Allium sativum at $20 \mathrm{ml} / \mathrm{litre}$ of water is can be beneficial to intestinal development and liver health of broiler. 


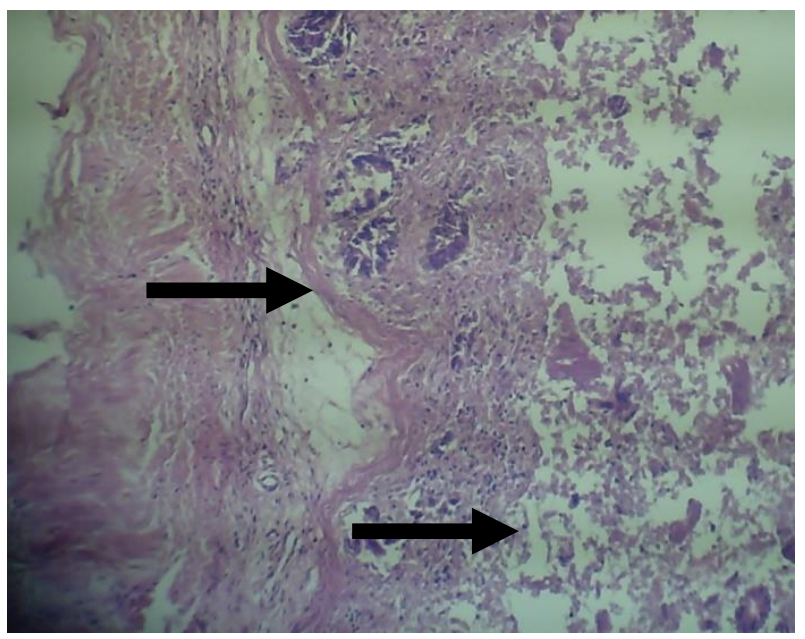

Plate 1: Duodenal villi Histology of Broiler chickens under the positive control group at 56 days of age (Magnification 100X).

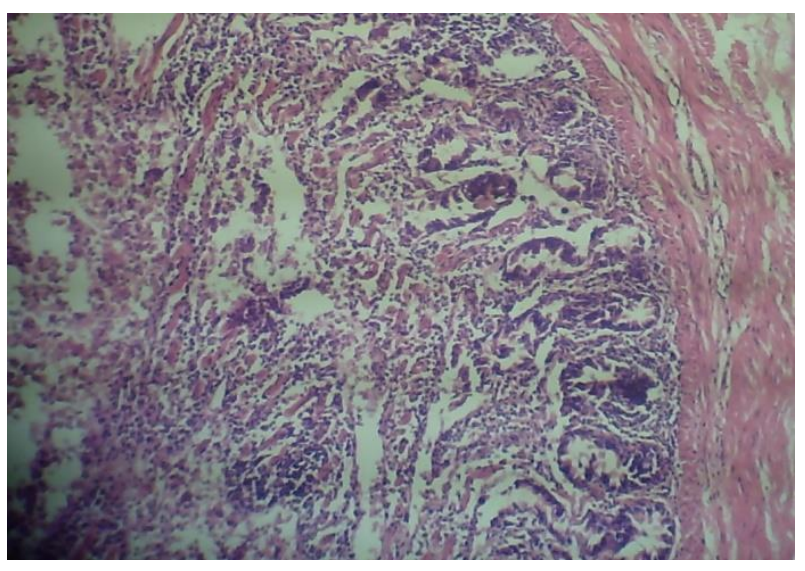

Plate 2: Duodenal villi Histology of Broiler chickens under the negative control group at 56 days of age (Magnification 100X).

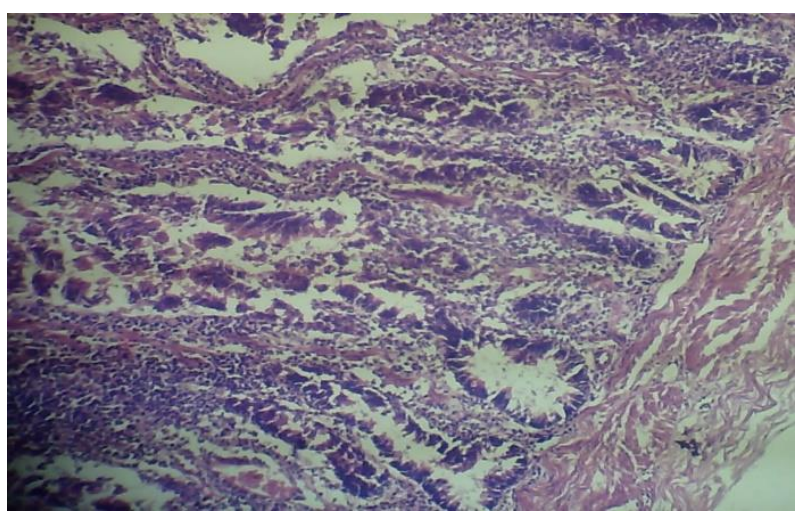

Plate 3: Duodenal villi Histology of Broiler chickens administered Aristolochia ringens extract at 20ml/1liter of drinking water at 56 days of age (Magnification 100X). 


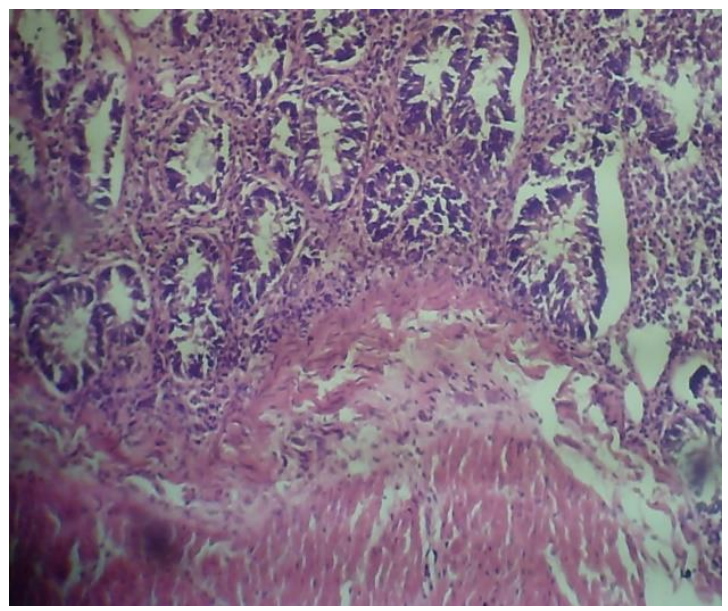

Plate 4: Duodenal villi Histology of Broiler chickens administered Allium sativum extract at $20 \mathrm{ml} / 1$ liter of drinking water at 42 days of age (Magnification 100X).

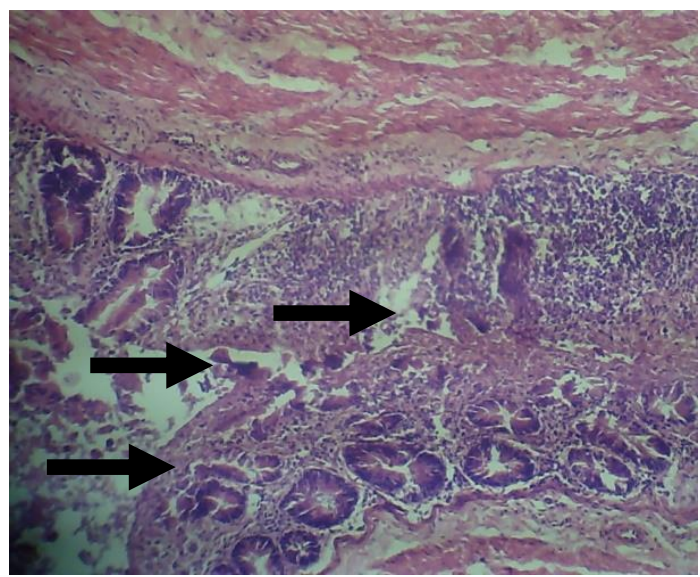

Plate 5: Duodenal villi Histology of Broiler chickens administered Occium grattissium extract at 20ml/1liter of drinking water at 42 days of age (Magnification 100X).

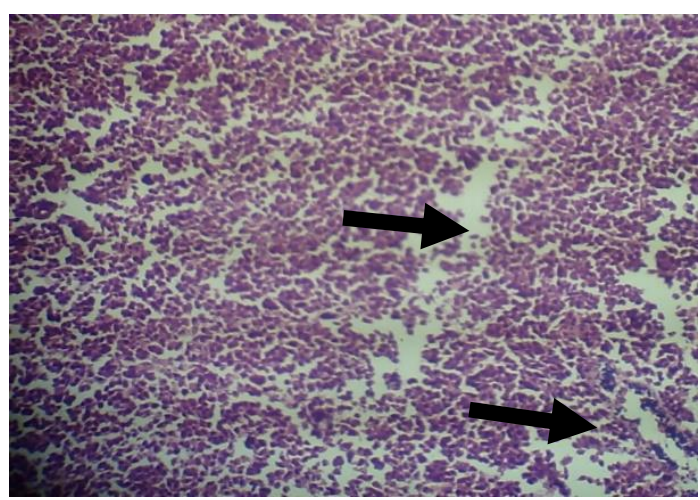

Plate 6: Liver Histology of Broiler chickens under the positive control group at 42 days of age (Magnification 100X). 


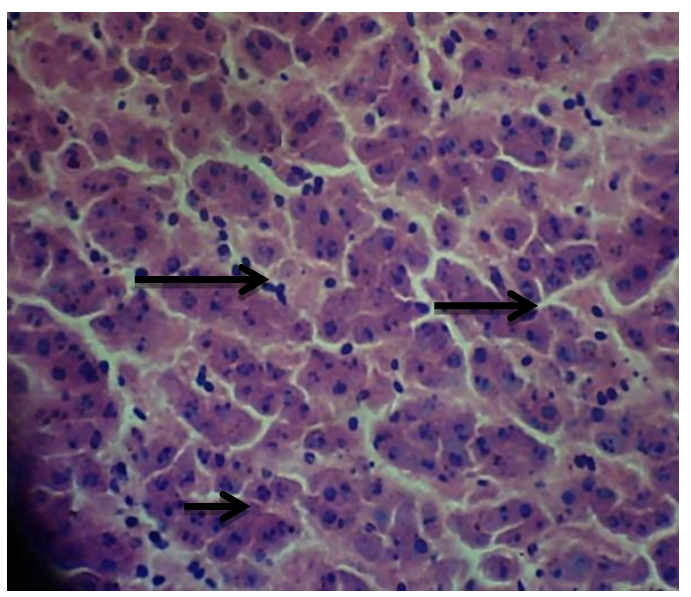

Plate 7: Liver Histology of Broiler chickens under the negative control group at 42 days of age (Magnification 100X).

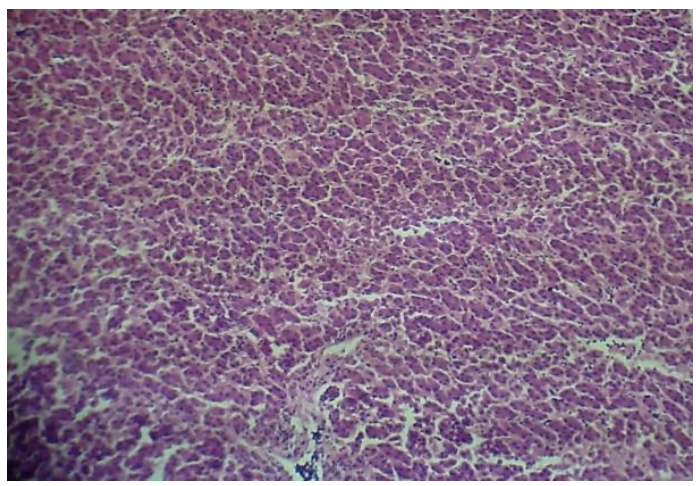

Plate 8: Liver Histology of Broiler chickens administered Aristolochia ringens extract at $20 \mathrm{ml} / 1$ liter of drinking water at 42 days of age (Magnification 100X).

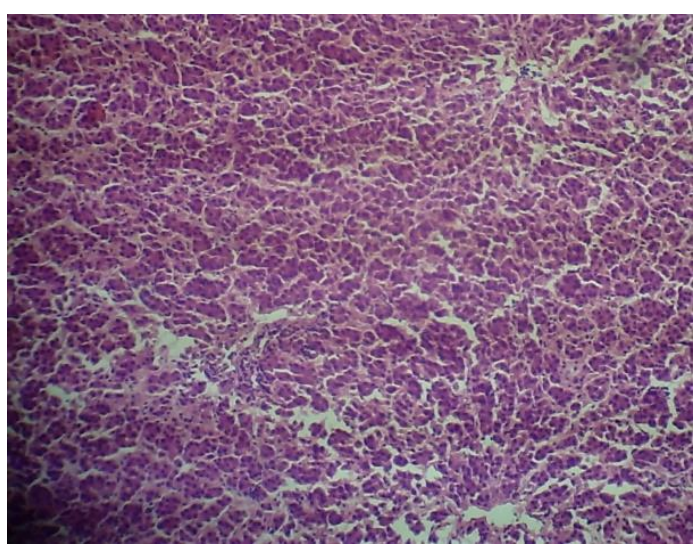

Plate 9: Liver Histology of Broiler chickens administered Allium sativum extract at 20ml/1liter of drinking water at 42 days of age (Magnification 100X). 


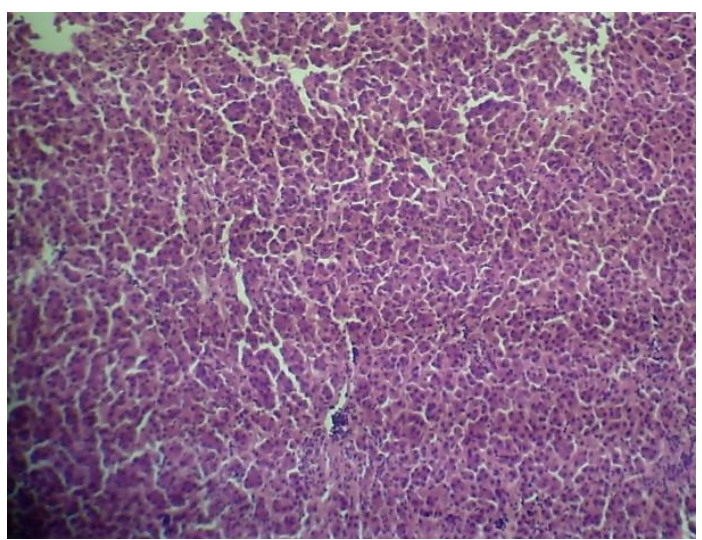

Plate 10: Liver Histology of Broiler chickens administered Occium grattissium extract at 20ml/1liter of drinking water at 42 days of age (Magnification 100X).

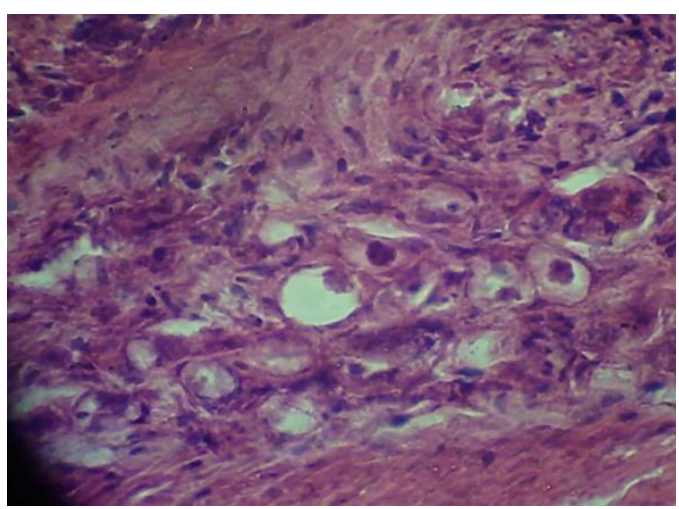

Plate 11: Caeca Histology of Broiler chickens under the positive control group at 42 days of age (Magnification 100X).

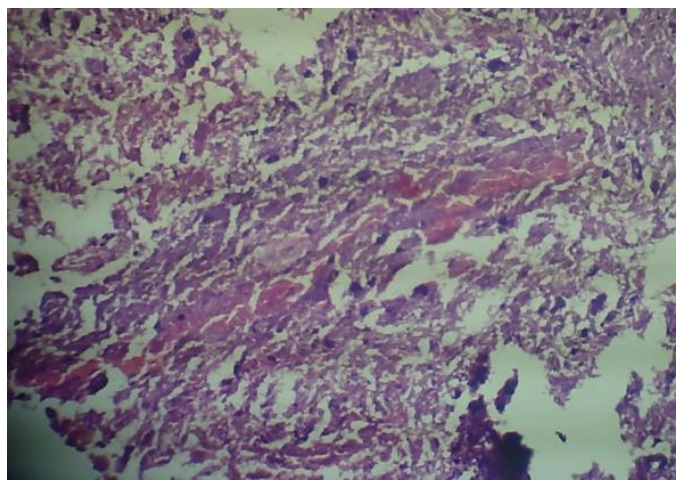

Plate 12: Caeca Histology of Broiler chickens under the negative control group at 42 days of age (Magnification 100X). 


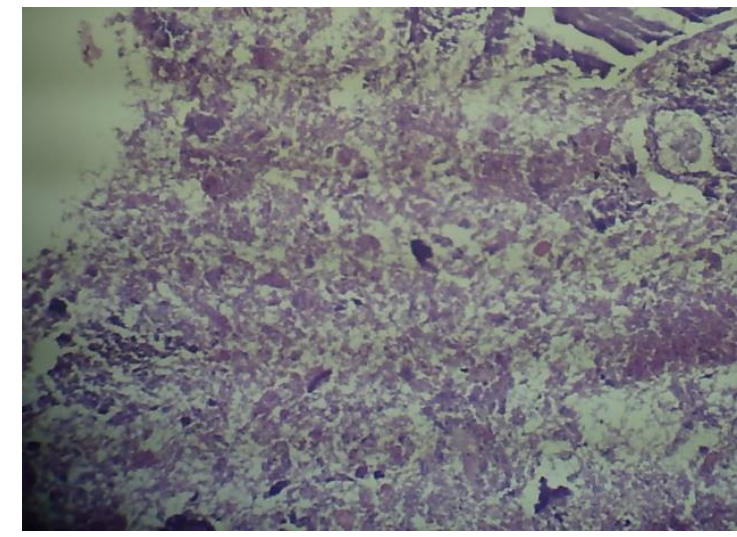

Plate 13: Caeca Histology of Broiler chickens administered Aristolochia ringens extract at $20 \mathrm{ml} / 1$ liter of drinking water at 42 days of age (Magnification 100X).

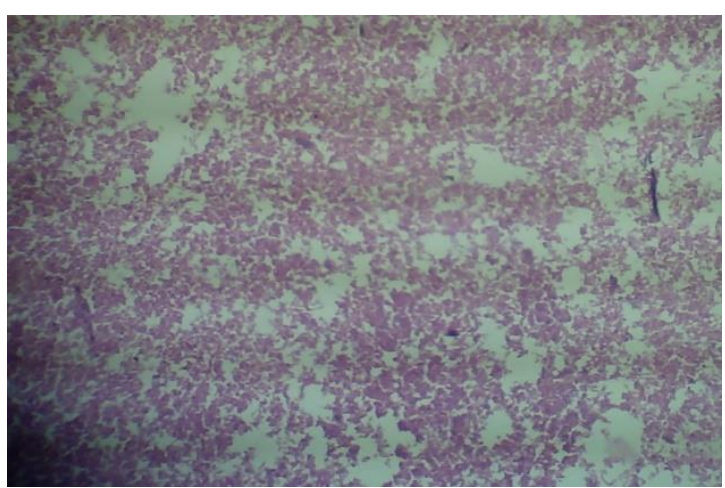

Plate 14: Caeca Histology of Broiler chickens administered Allium sativum extract at $20 \mathrm{ml} / 1$ liter of drinking water at 42 days of age (Magnification 100X).

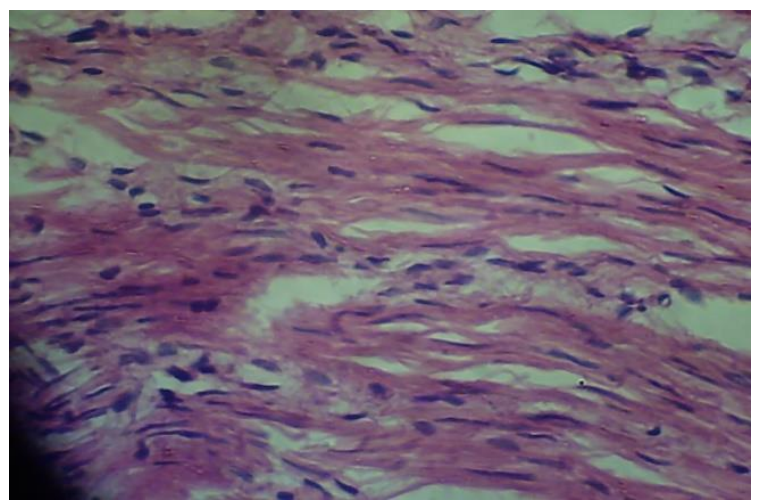

Plate 15: Caeca Histology of Broiler chickens administered Occium grattissium extract at 20ml/1liter of drinking water at 42 days of age (Magnification 100X). 


\section{REFERENCES}

B. J. Divya, B. Suman, M. Venkataswamy and K. Thyagaraju. A study on phytochemicals, functional groups and mineral composition of allium sativum (garlic) cloves (2017). International journal of current phytochemical research, 9(3): 42-45.

Diarra M. S., Malouin F (2014). Antibiotics in Canadian poultry productions and anticipated alternatives. Frontiers in Microbiology, 5:15.

Edeoga H.O. and Eriata, D.O. (2001) Alkaloids,Tannins and contents of some Nigeria medicinal plants. Journal of Medicinal Aromatic Plants Science, 23: 21-25.

Faisal Ferdous, Shafiul Arefin, Moshiur Rahman, Mustafijur Rahman Ripon, Harunur Rashid, Rokeya Sultana, Muhammad Tofazzal Hossain, Muslah Uddin Ahammad, and Kazi Rafiq (2019). Beneficial effects of probiotic and phytobiotic as growth promoter alternative to antibiotic for safe broiler production. Journal of advanced veterinary and animal research, 6(3): 409-415.

Fasola, T.R., Oluwole, M.E., Obatayo, O. and Obayagbo, S.E (2015). The antimicrobial potential and phytochemical composition of Aristolochia ringens Vahl. Advances in Life Science and Technology. 29, 5-12.

Joshua Adamu Tende, Joseph Olusegun Ayo, Aliyu Mohammed, Abdulkadir Umar Zezi (2014). Effect of garlic (Allium sativum) and ginger (Zingiber officinale) extracts on haematobiochemical parameters and liver enzyme activities in Wistar rats. International Journal of Nutrition and Food Sciences, 3:380-420.

Klaunig, J.E., Babich, M.A., Baetcke, K.P., Cook, J.C., Corton, J.C., David, R.M., and Roberts, R.A (2003). PPARa agonist-induced rodent tumors: modes of action and human relevance. Critical reviews in toxicology, 33(6), 655-780

Mabberley, D.J (1993). The Plant Book. Department of Plant Science, University of Oxford Press Syndicate of the University of Cambridge, p. 707.

Obonga Wilfred, Philip F. Uzor, Emmanuel O. Ekwealor and Sampson C. Nwabuko (2018). Comparative Phytochemical, Antioxidant and Antimicrobial Properties of Ficus capensis, Aristolochia ringens, Albizia zygia and Lannea welwitschii. Dhaka university journal of pharmaceutical sciences, 16(2): 147.

Olorunsogbon (2017). Biochemical And Haematological Effect Of Three Medicinal Plants Extract Used Therapeutically On Broiler Chickens As Anticoccidial And Growth Promoter. SosPoly Journal of Science \& Agriculture, Vol. 2, ISSN: 2536-7161.

Osho, I.B. and Lajide, L. (2014). Antitrypanosomal activity of Aristolochia ringens against Trypanosoma congolense infection in mice. Journal of Pharmacognosy and Phytotherapy. 6, 1-3. 
Priscilla Alexander (2016). Phytochemical Screening And Mineral Composition Of The Leaves Of Ocimum Gratissimum (Scent Leaf). International Journal of Applied Sciences and Biotechnology, 4(2): 161-165.

Rifat Khan, V. Tufarelli, Z. Nikousefat and S. Naz (2012). Garlic (Allium sativum) supplementation in poultry diets: Effect on production and physiology. World's Poultry Science Journal 68(3):417-424.

Ripon Mustafijur Rahman, Faisal Ferdous, Moshuir Rahman and Reyed-ul-Ferdous (2019). Dose-dependent response to phytobiotic supplementation in feed on growth, hematology, intestinal $\mathrm{pH}$, and gut bacterial load in broiler chicken, Journal of advanced veterinary and animal research, ISSN 2311-7710.

Sklan, D. 2001. Development of the digestive tract of poultry. Poultry Science, 57:415-428.

Wichtl M (2004). Herbal drugs and phytopharmaceuticals, A hand book for practice on a scientific basis. 3rd Edn. Boca Raton, FL: CRC Press.

Uni, Z., S. Ganot, and D. Sklan (1998). Post hatch development of mucosal function in the broiler small intestine. Poultry Science. 77:75-82.

Yang, B., Kortesniemi, M., Liu, P., Karonen, M., and Salminen, J.P (2012). Analysis of hydrolysable tanins and other phenolic compounds in emblic leafflower (phyllanthus emblica L.) fruits by high performance liquid chromatography-electrospray ionization mass spectrometry. 